\title{
Controle Químico de BRILhantina (Pilea microphylla) no Cultivo de ORQuídeas ${ }^{1}$
}

\author{
Chemical Control of Pilea microphylla in Orchid Cultivation
}

\author{
FREITAS, F.C.L. ${ }^{2}$, GROSSI, J.A.S. ${ }^{3}$, BARROS, A.F. ${ }^{4}$, MESQUITA, E.R. ${ }^{4}$, FERREIRA, F.A. ${ }^{5}$ e \\ BARBOSA, J.G. ${ }^{3}$
}

\begin{abstract}
RESUMO - Este trabalho teve como objetivo avaliar a eficácia do oxyfluorfen no controle da brilhantina (Pilea microphylla) em cultivo de orquídeas. Foram realizados dois experimentos, no delineamento de blocos ao acaso, no esquema fatorial $2 \times 7$, com três repetições. Um dos experimentos foi constituído por duas espécies de orquídeas (Epidendrum ibaguensis $e$ Dendrobium sp.) e sete doses de oxyfluorfen $\left(0,000,0,024,0,072,0,144,0,216,0,288\right.$ e $0,36 \mathrm{~L} \mathrm{ha}^{-1}$ do i.a.), pulverizadas em área total, e o outro, pelas mesmas espécies e sete concentrações de oxyfluorfen $(0,00000$ 0,00036, 0,00072, 0,00144, 0,00288, 0,00576 e 0,01152\% do i.a.), aplicadas em pulverização dirigida na brilhantina, sem atingir as folhas de orquídea. Cada unidade experimental foi representada por um vaso, com uma planta de orquídea, infestado com brilhantina. Aos 15, 30 e 60 dias após a aplicação do herbicida (DAA), foram realizadas avaliações visuais de toxidez na orquídea e de controle de brilhantina, utilizando-se a escala de 0 (ausência de toxidez) a 100 (morte das plantas). Não houve interação entre fatores, espécie e dose ou concentração do herbicida nem diferença no comportamento do herbicida entre as espécies, no que se refere às características avaliadas, em nenhum dos experimentos. Não foram observados sintomas de toxidez nas plantas de orquídea em nenhum dos tratamentos avaliados. Verificou-se controle eficiente de brilhantina, acima de $90 \%$, para as doses superiores a 0,26 e 0,25 $\mathrm{L} \mathrm{ha}^{-1}$, aos 30 e 60 dias DAA, respectivamente, na aplicação em área total; e nas concentrações superiores a 0,0020 e 0,0019\%, aos 30 e 60 DAA, respectivamente, na aplicação dirigida. O oxyfluorfen promoveu eficiente controle de brilhantina através da pulverização em área total e dirigida, sem causar danos às plantas de orquídeas.
\end{abstract}

Palavras-chave: oxyfluorfen, cultivo protegido, Orchidaceae, Epidendrum ibaguensis, Dendrobium sp. .

ABSTRACT - This study aimed to evaluate the efficacy of oxyfluorfen in the control of Pilea microphylla in orchid cultivation. Two experiments were carried out in a randomized block design, arranged in a factorial scheme $2 \times 7$, with three replicates. One trial was composed by two orchid species (Epidendrum ibaguensis and Dendrobium sp.) and seven oxyfluorfen rates $\left(0.000,0.024,0.072,0.144,0.216,0.288\right.$ and $0.36 \mathrm{~L} \mathrm{ha}^{-1}$ of i.a.), sprayed over the total area and the other was composed by the same species and seven oxyfluorfen concentrations (0.00000, 0.00036, 0.00072, 0.00144, 0.00288, 0.00576 and $0.01152 \%$ of i.a.), directly sprayed without reaching the orchid leaves. Each experimental unit was represented by a pot with an orchid plant infested with Pilea microphylla. At 15, 30 and 60 days after application (DAA) visual evaluations of toxicity on orchid and Pilea microphylla control were performed, using a scale from $O$ (toxicity absence) to 100 (plant death). No interaction between species and rate or concentration of herbicide and no difference in herbicide behavior or symptoms of toxicity on orchid plants were observed in either experiment. Efficient control of Pilea microphylla was verified

1 Recebido para publicação em 6.11.2006 e na forma revisada em 4.7.2007.

2 Professor Adjunto - DCV/UFERSA, Dep. de Ciências Vegetais, Universidade Federal Rural do Semi-Árido , 59.625-900. Mossoró-MG, <fclaudiof@yahoo.com.br>; ${ }^{3}$ Professor Adjunto - DFT/UFV; ${ }^{4}$ Estudante de Agronomia - DFT/UFV; ${ }^{5}$ Professor Titular - DFT/UFV. 
for rates superior to 0.26 and $0.25 \mathrm{~L} \mathrm{ha}^{-1}$ at 30 and $60 \mathrm{DAA}$, respectively, in the total area application, and for concentrations superior to 0.0020 and $0.0019 \%$, at 30 and 60 DAA, respectively in direct spray. Oxyfluorfen provided efficient control of Pilea microphylla with spray in total area and direct spray, without harming the orchid plants.

Keywords: oxyfluorfen, greenhouse crops, orchidaceae, Epidendrum ibaguensis, Dendrobium sp.

\section{INTRODUÇÃO}

As Orchidaceae constituem uma das maiores familias de plantas ornamentais e encontram-se distribuidas por quase todo o mundo, representando o grupo mais evoluído da super ordem Liliiflorae (Dressler, 1993), com alto poder de adaptação a diferentes ambientes: terrestres, epífitas ou rupícolas (Benzing et al., 1982).

A maior importância das Orchidaceae está no potencial ornamental de suas flores, que se destacam por sua singular beleza. Assim, o cultivo de orquídeas, em vasos, para fins comerciais tem se tornado cada vez mais expressivo. No entanto, tem-se observado, comumente, a infestação dos vasos de orquídeas com brilhantina (Pilea microphylla), planta perene, herbácea, prostrada, muito ramificada, com 10 a $20 \mathrm{~cm}$ de comprimento e que se propaga por sementes (Lorenzi, 2000). Essa planta afeta o desenvolvimento das orquídeas, aumentando o custo de produção e reduzindo o seu valor comercial.

O controle da brilhantina é realizado, normalmente, por meio de capina manual, podendo ocorrer rebrota caso a planta não seja totalmente eliminada, uma vez que ela emite, facilmente, novas brotações na região do coleto. Além disso, a produção elevada de sementes - que são de fácil transporte pelo vento - promove rápida reinfestação.

A utilização de herbicidas no controle de plantas daninhas em cultivo de orquídeas, aliada a outras práticas de controle, pode vir a ser uma alternativa importante. Contudo, a literatura carece de trabalhos específicos. Avaliando a seletividade e a eficácia de diversos herbicidas para controle da brilhantina em cultivo de bromélias, Freitas et al. (2004) verificaram que o oxyfluorfen controlou com eficiência as plantas de brilhantina em aplicação dirigida, sem causar nenhuma toxidez às plantas de bromélia.

O oxyfluorfen é um herbicida que, quando aplicado em pós-emergência, provoca fechamento estomático e deterioração das membranas celulares. Aplicado em pré-emergência, age sobre o hipocótilo e epicótilo das plantas em emergência e nos meristemas foliares, não apresentando nenhuma ação sobre os tecidos radiculares. A meia-vida no solo é de 30 a 40 dias, podendo apresentar efeito residual até seis meses depois da aplicação (Rodrigues \& Almeida, 2005). Sua degradação é essencialmente por fotólise, fazendo com que em áreas com condições de umidade e sombreamento seu período residual seja mais prolongado (Rodrigues \& Almeida, 2005; Cassamassimo, 2005).

Este trabalho teve como objetivo avaliar a seletividade e a eficácia do oxyfluorfen no controle de brilhantina (Pilea microphylla) em cultivo de orquídeas.

\section{MATERIAL E MÉTODOS}

Foram realizados dois experimentos, sob telado de sombrite, com $50 \%$ de sombreamento, na Unidade de Floricultura do Departamento de Fitotecnia da Universidade Federal de Viçosa, onde foram avaliados dois métodos de aplicação do oxyfluorfen, no delineamento em blocos ao acaso, no esquema fatorial $2 \times 7$, com três repetições, entre os meses de janeiro e maio de 2005.

Um dos experimentos foi constituído por duas espécies de orquídea (Epidendrum ibaguensis e Dendrobium sp.) e sete doses de oxyfluorfen $(0,000,0,024,0,072,0,144,0,216$, 0,288 e $0,36 \mathrm{~L} \mathrm{ha}^{-1}$ do i.a.), pulverizadas em área total; e o outro, pelas mesmas espécies e sete concentrações do herbicida $(0,00000$, 0,00036, 0,00072, 0,00144, 0,00288, 0,00576 
e 0,01152\% do i.a.), aplicadas em pulverização dirigida na brilhantina, sem atingir as folhas de orquídea. Cada parcela foi constituída de um vaso, enchido com um litro de pó de xaxim, infestado com brilhantina, e contendo uma planta de orquídea. A cada semana, o substrato dos vasos foi adubado com 0,25 grama de solução nutritiva contendo $15,00,30,00,20,00$, $1,10,0,40,4,00,0,10,0,03,0,05$ e $0,05 \%$ de $\mathrm{N}$, $\mathrm{P}, \mathrm{K}, \mathrm{Ca}, \mathrm{Mg}, \mathrm{S}, \mathrm{Fe}, \mathrm{Mn}, \mathrm{B}$ e $\mathrm{Zn}$, respectivamente.

No experimento cuja aplicação do oxyfluorfen foi realizada em área total, foi utilizado pulverizador costal, mantido à pressão constante pelo $\mathrm{CO}_{2}$, equipado com barra com dois bicos XR 11002 , espaçados de $50 \mathrm{~cm}$, mantidos à altura de $50 \mathrm{~cm}$ do ápice das plantas de orquídea, à pressão de $250 \mathrm{kPa}$, com volume de calda de $200 \mathrm{~L} \mathrm{ha}^{-1}$.

No experimento com aplicação dirigida do oxyfluorfen foi utilizado, também, o pulverizador costal, mantido à pressão constante pelo $\mathrm{CO}_{2}$, equipado com um bico de cone vazio, modelo TX 8002, à pressão de $200 \mathrm{kPa}$. A aplicação da calda foi direcionada, procurando atingir somente as plantas de brilhantina, molhando até o ponto de pré-escorrimento e evitando o contato com as folhas de orquídea.

No momento da aplicação, a temperatura e umidade relativa do ar eram, respectivamente, de $25{ }^{\circ} \mathrm{C}$ e $85 \%$, e a velocidade do vento, de $2 \mathrm{~km} \mathrm{~h}^{-1}$. As plantas de orquídea estavam com aproximadamente $25 \mathrm{~cm}$ de altura, e a brilhantina, com cerca de $3 \mathrm{~cm}$.

Aos 15, 30 e 60 dias após a aplicação do herbicida (DAA), foram realizadas avaliações visuais de toxidez na orquídea e de controle de brilhantina, utilizando-se a escala de 0 (ausência de toxidez) a 100 (morte das plantas).

Em ambos os experimentos, os dados obtidos foram submetidos à análise de variância; os dados referentes ao controle da brilhantina foram também submetidos à análise de regressão. Os modelos adotados foram devido à explicação biológica, à significância do quadrado médio da regressão e ao coeficiente de regressão.

\section{RESULTADOS E DISCUSSÃO}

Nos dois experimentos, com dose e concentração de oxyfluorfen, o comportamento do herbicida foi semelhante nas duas espécies de orquídeas estudadas, não tendo sido observada, também, interação entre fatores, espécie e dose ou concentração do herbicida, em se tratando das características avaliadas (controle de brilhantina e toxidez em plantas de orquídeas). Portanto, os dados apresentados foram obtidos a partir da média das duas espécies de orquídea estudadas.

O oxyfluorfen não causou efeito tóxico nas plantas de orquídea nas avaliações realizadas para os dois experimentos, demonstrando a seletividade do herbicida para as espécies de orquídeas estudadas (Epidendrum ibaguensise Dendrobium sp.). Freitas et al. (2004) também não constataram nenhuma toxidez desse herbicida em plantas de bromélia, em aplicação dirigida.

Na Figura 1, observa-se que o controle de brilhantina foi superior a $90 \%$ nas doses superiores a 0,26 e $0,25 \mathrm{~kg} \mathrm{ha}^{-1}$ de oxyfluorfen, respectivamente, aos 30 e 60 DAA, na aplicação em área total. Avaliando o mesmo herbicida na cultura da cebola em semeadura direta, Ferreira et al. (2000) verificaram controle eficiente de Amaranthus hybridus e Galinsoga parviflora a $0,192 \mathrm{~kg} \mathrm{ha}^{-1}$, dose esta que não foi eficiente no controle de Lepidium verginicum e Coronopus didymus, aos 58 DAA.

$\mathrm{Na}$ aplicação dirigida, verificou-se controle acima de $90 \%$ para as concentrações superiores a 0,0020 e 0,0019\% de oxyfluorfen, aos 30 e 60 DAA, respectivamente (Figura 2). As concentrações de oxyfluorfen encontradas neste trabalho, em aplicação dirigida, foram inferiores às observadas por Freitas et al. (2004), que foram de 0,0192 e 0,0168\%, aos 20 e 60 DAA, respectivamente, para controle da brilhantina em vasos de cultivo de bromélia.

Tanto na aplicação dirigida quanto naquela em área total, o oxyfluorfen não somente foi eficiente no controle da brilhantina, como evitou a reinfestação, mantendo os vasos de orquídeas livres de plantas daninhas durante o período experimental, por apresentar bom ef ei to residual no substrato. Segundo Rodrigues \& Almeida (2005), o efeito residual 


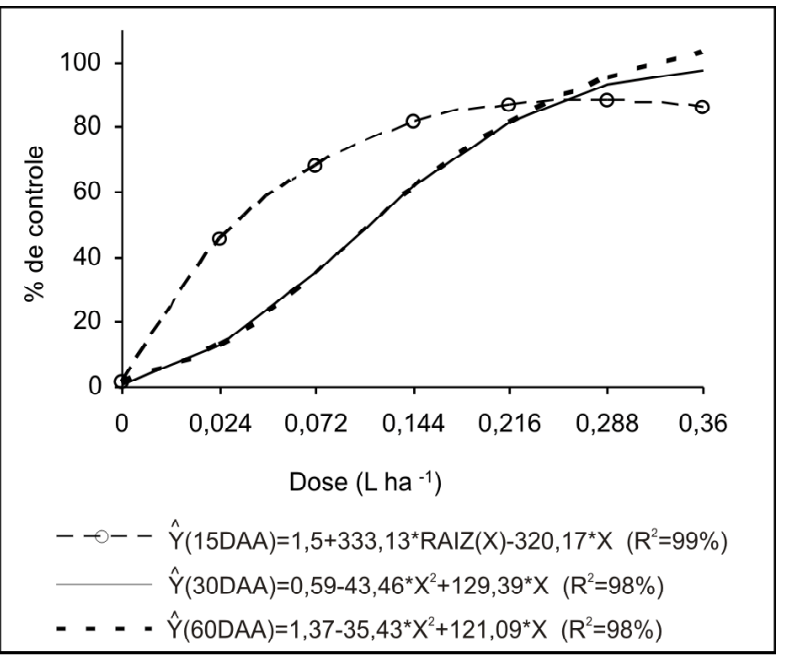

Figura 1 - Controle de brilhantina em função das doses de oxyfluorfen, aplicadas em área total, nas avaliações realizadas aos 15, 30 e 60 dias após aplicação (DAA).

do oxyfluorfen é mais prolongado em ambiente com umidade elevada e protegido da incidência de raios solares, visto que sua principal rota de degradação é a fotólise. Ta mbém, Cassamassimo (2005), avaliando a dissipação de oxyfluorfen em solos com atividades florestais, sombreados e a pleno sol, constatou dissipação mais lenta do herbicida nas áreas sombreadas, enquanto Yen et al. (2003) verificaram que temperaturas elevadas aumentam a taxa de dissipação do oxyfluorfen. Assim, sua ação, neste trabalho, pode ter sido prolongada, uma vez que o substrato nos vasos foi mantido em ambiente protegido, com $50 \%$ de sombreamento e umidade em torno de $80 \%$ da capacidade de campo, mantida por meio de irrigações diárias.

Os resultados mostram que os dois métodos de aplicação, em área total e dirigida, foram eficientes no controle de brilhantina, sem causar intoxicação às plantas de orquídea. Por motivos operacionais, a aplicação em área total é mais indicada no caso de plantas pequenas e/ou sem área foliar expressiva, enquanto a aplicação dirigida é mais adequada a plantas com maior área foliar, a fim de evitar o "efeito guarda-chuva", que impede o acesso das gotas pulverizadas às plantas daninhas, sendo esse processo bem mais moroso.

O oxyfluorfen promoveu excelente controle de brilhantina e evitou a reinfestação, mantendo



Figura 2 - Controle de brilhantina em função das concentrações de oxyfluorfen, em aplicação dirigida, nas avaliações realizadas aos 15, 30 e 60 dias após aplicação (DAA).

os vasos de orquídea livres de plantas daninhas durante o período experimental (Figura 3), em razão de apresentar bom efeito residual no substrato, potencializado pelas condições de cultivo protegido, com sombreamento e umidade adequada.

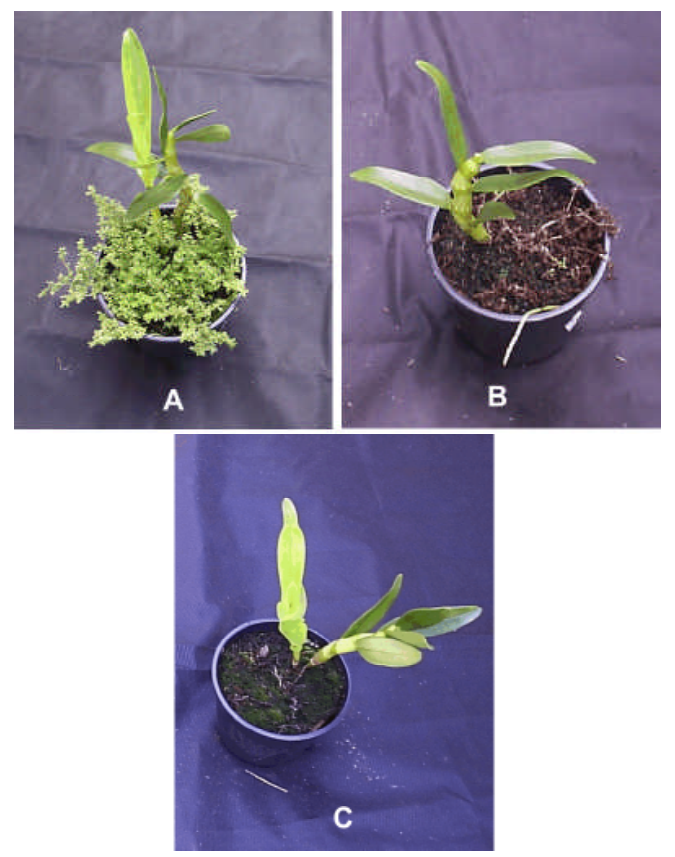

Figura 3 - Vasos de orquídeas sem aplicação de herbicida (A), com $0,36 \mathrm{~L} \mathrm{ha}^{-1}$ de oxyfluorfen aplicado em área total (B) e $0,00288 \%$ de oxyfluorfen em aplicação dirigida (C), aos 60 dias após a aplicação, para a espécie Dendrobium sp. 


\section{LITERATURA CITADA}

BENZING, D. H.; OTT, D. W.; FRIEDMAN, W. E. Roots of Sobralia macrantha (Orchidaceae): structure and function of the velamen-exodermis complex. Am. J. Bot., v. 69, p. 608-614, 1982.

CASSAMASSIMO, R. E. Dissipação e mobilidade dos herbicidas gliphosato e oxyfluorfen em solos com atividades florestais. 2005. $62 \mathrm{f}$. Dissertação (Mestrado em Recursos Florestais) - Escola Superior de Agricultura Luiz de Queiroz, Piracicaba, 2005.

DRESSLER, R. L. Phylogeny and classification of the orchid family. Portland: Dioscorides Press, 1993. 314 p.

FERREIRA, L. R. et al. Seletividade e eficácia da aplicação seqüencial de oxyfluorfen e de ioxynil-octanoato, em semeadura direta de cebola. Planta Daninha, v. 18, n. 1, p. 39-50, 2000.
FREITAS, F. C. L. et al. Controle químico de plantas danin has em bromeliários. In: CONGRESSO BRASILEIRO DA CIÊNCIA DAS PLANTAS DANINHAS, 24., 2004, São Pedro. Resumo Expandido... São Pedro: 2004 . CDROM.

LORENZI, H. Plantas daninhas do Brasil: terrestres, aquáticas, parasitas e tóxicas. 3. ed. Nova Odessa: Instituto Plantarum, 2000. 608 p.

RODRIGUES, B. N.; ALMEIDA, F. S. Guia de herbicidas. 3. ed. Londrina: IAPAR, 2005. 591 p.

YEN, J. H.; SHEU, W. S.; WANG, Y. S. Dissipation of the herbicide oxifluorfen in subtropical soils and its potential to contaminate groundwater. J. Ecotoxicol. Environ. Safety, v. 54, n. 2, p. 151-156, 2003. 